\title{
Vested rights, active aging and resiliance: the importance of such concepts throughout life
}

2016 is engraved on everyone's memory due to the profound economic, political and social crisis that Brazil has been undergoing. Although the triggers of this crisis are to be found in previous years, it worsened over the course of the year and I believe we have yet to reach the nadir. The repercussions of the crisis are extremely worrying. The numbers of the unemployed (including those who are working less than they could and they would like) already exceed $20 \%$ and projections indicate that this percentage is likely to increase in 2017. Many elderly persons have become the main resource providers for their whole family, and purchasing power continues to fall. Our social policies have been made fragile and our public institutions weakened. The health sector has undergone repeated cuts. Public hospitals offer ever more unstable services. Unemployment has led millions to lose their health insurance. Inevitably, all this has affected the well-being of millions of elderly people. In several states, many do not receive their pensions on time. There are major uncertainties about the nature of the proposed pension reforms, which seem to me to be inevitable. In 2016, urban social security spending reached a total of $\mathrm{R} \$ 150$ billion, and if nothing changes, this number will increase exponentially. Such spending has become unsustainable in its present form. Brazil cannot remain among the very few countries where there is no minimum retirement age and where the average retirement age is only 54-52 for women and 56 for men. Life expectancy has reached more than 75 years, while the social security plan has not changed since it was conceived in an era when such expectancy was barely over 40 years. The implementation of such reforms, however, is highly sensitive. There are vested rights at stake, as well as expectations that if not handled properly, could generate major social instability. It is essential that all groups are heard from the bottom up, and that reform does not take the form of an imposition from above, passed by a Legislative whose credibility has been put under question by the actions of its own members.

This scenario reinforces the importance of planning policies that embrace the principles of active aging, as defined by the World Health Organization in 2002. In that year, at the United Nations Assembly on Aging, the WHO launched its policy framework on active aging, defining it as the process of optimizing opportunities for bealth, participation and security/protection in order to enbance quality of life as people age. To these pillars, our Centro Internacional da Longevidade-Brasil (International Longevity Center, Brazil) (ILC-Brazil) added a fourth - that of lifelong learning - in the document "Active Aging: A Political Framework in response to the Longevity Revolution" (www.ilcbrazil.org). In practice, for the aging individual, regardless of age, this definition presupposes the accumulation of four essential capitals for positive aging: health, intellectual capital, social capital and financial capital (Exame magazine, January 18, 2017, page 33). The earlier we start to accumulate these capitals the better, but it is never too late. However, responsibility does not lie with the individual alone. It is imperative that the public sector does its part, and accompanies the situation. It is also 
necessary for academia, non-governmental institutions, the private sector and the media to facilitate the process. In October 2016, ILC-Brazil organized the IV International Forum on Longevity with the theme of "the function of design and technology in a more long-lived society". The document arising from the event (www.ilcbrazil.org) sets out the principles which should guide the various sectors of society regarding the objective of developing products, services and policies that are friendlier to the elderly - and thus to people of all ages.

In recent years, the concept of resilience has gained increasing space in gerontological discussion. And here it is a word of hope. Studies have shown that the elderly are often vulnerable. However, they have also shown that, above all, they are resilient (Annual Review of Gerontology and Geriatrics, Volume 32, 2012 Emerging Perspectives on Resilience in Adulthood and Later Life). As far as the development of policies related to aging is concerned, as well as in the field of gerontological research, which explores its multiple dimensions and wide range of determinants, I believe that in coming years we will learn more and come to understand the importance of the following concept throughout the course of life - resilience: access to the reserves necessary to adapt, support or grow from the challenges encountered in life" (ILCBrazil.org).

Alexandre Kalache

President, Centro Internacional da Longevidade (International Longevity Center) - Brazil

RBGG Editor 